\title{
BUDGET PRACTICES AND ONE-YEAR SALARY CASE IN THE OTTOMAN EMPIRE
}

\author{
DOI: 10.17261/Pressacademia.2018.924 \\ PAP- V.7-2018(77)-p.403-407
}

\section{Nurullah Karta}

Yuzuncu Yil University, Van, Turkey.

nkarta25@gmail.com, ORCID: 0000-0003-2798-7012.

To cite this document

Karta, N. (2018). Budget practices and one-year salary case in the Ottoman Empire. PressAcademia Procedia (PAP), V.7, p.403-407.

Permemant link to this document: http://doi.org/10.17261/Pressacademia.2018.924

Copyright: Published by PressAcademia and limited licenced re-use rights only.

\begin{abstract}
Purpose- When the financial structure of the Ottoman Empire was examined, a similar budget implementation as in Western countries was organized in 1855 with the central administration budget for the first time, in other words the general budget under the name of " Hazine-i Celile Muvazene Defterinin Suret-I Tanzimine Dair Nizamname"

Methodology- Although there is no current budget practice as it is now, there is some kind of definite accounts documenting the yearly income and expenditures of the central treasury and reflecting the final accounts of the year. In this framework, the Ottomans were allocating the revenues from certain sources to certain services. In this period, the calculation of the state revenues and the annual expenditures of the public expenditures and the registration of the records were done. Income was not based on expenses, instead the expenses was based on income.

Findings- Therefore, although the Ottoman Empire did not have a proper budget structure as it is in present time, it does not mean that the income and expenses were not recorded. As a matter of fact, this study will examine the possession of a bureaucratic state structure of the Ottomans and emphasize that every financial practice is kept a record.

Conclusion- In addition, this study will focus on how the Ottoman Empire had set out a budget policy since its foundation and explain the importance of transition into Western budgetary practices. However, based on the sources of the Prime Ministry Ottoman archives, one year salary conditions will be tried to be determined according to the month income of the top level official of the Ottoman Empire of 1887.
\end{abstract}

Keywords: Budget, Ottoman Empire, salary, financial structure, definite account.

JEL Codes: N00, Z00, O10.

\section{OSMANLI IMPARATORLUĞU'NDA BÜTÇE UYGULAMALARI VE BIR YILLIK MAAŞ ÖRNEĞi}

\section{ÖZET}

Amaç- Osmanlı İmparatorluğunun mali yapısı incelendiğinde Batılı ülkelerde ki uygulamalara benzer bütçe uygulaması, 1855'de ilk kez merkezi idare bütçesi diğer bir ifade ile genel bütçe, "Hazine-i Celile'nin Muvazene Defterinin Suret-i Tanzimine Dair Nizamname" adı ile düzenlenmiştir.

Yöntem- Günümüzde ki bütçe uygulaması olmasa da devletin merkezi hazinesine ait bir yıllık gelir ve giderlerini kayıt altına alan ve yılsonu kesin hesap durumlarını yansıtan bir çeşit kesin hesap belgeleri mevcuttu.

Bulgular- Bu çerçevede Osmanlılar belli kaynaklardan elde edilen gelirlerin belli hizmetlere tahsisini gerçekleştirmekte idi. Bu dönemde devlet gelirleri ile kamu giderlerinin yıldan yıla hesaplanması ve deftere kaydedilmesi usuldendi. Gidere göre gelir değil gelire göre gider esas alınmaktaydı. Dolayısıyla Osmanlı İmparatorluğunun her ne kadar günümüze uygun bir bütçe yapısına sahip olmaması gelir ve giderlerinin kayır altına alınmadığı anlamına gelmez. Nitekim bu çalışmamızda Osmanlıların bürokratik bir devlet yapısına sahip olması irdelenecek ve her mali uygulamanın kaydının tutulduğu vurgulanacaktır.

Sonuç- Ayrıca Osmanlı İmparatorluğunun kuruluştan itibaren nasıl bir bütçe politikası belirledikleri üzerinde durulacak ve Batılı anlamda bütçe uygulamalarına neden geçildiğinin önemi açıklanacaktır. Bununla birlikte Başbakanlık Osmanlı arşiv kaynaklarına dayalı olarak 1887 tarihli Osmanlı İmparatorluğunun üst düzey ricalinin aylara göre bir yıllık maaş durumları tespit edilmeye çalışılacaktır.

Anahtar Kelimeler: Bütçe, Osmanlı İmparatorluğu, maaş, mali yapı, kesin hesap. JEL Kodları: N00, Z00, O10. 


\section{GíRiş}

Osmanlı Devleti ilk başlarda gelir giderlerini kayıt altına alırken harcamalarını şer'i hükümlere göre "tahsisat varidat usulü" şeklinde bir uygulamaya göre gerçekleştirirdi. (Feyzioğlu; 1981:26) Harc-ı Hassa Defteri her aya mahsus ayrı ayrı yapılan sarfiyatı ve o aylardaki varidatı göstermesi bize önemli bir ip ucu vermektedir. Bu bakımından devlet bütün harcamaları ve gelirleri kayıt altına alması uygulaması Osmanlı Devleti'nin bir diğer özelliği olan bürokratik devlet olma vasfını göstermektedir. Osmanlı Devletinde her yıl bütçe düzenlemesi yapılmaktaydı. Yıl sonu itibariyle gelir-gider hesaplarının gösteren bir cetvel düzenlenir, hazineye giren meblağın ne kadarının harcandığını kayıt edilirdi. Kısacası devlet gidere göre değil gelire göre bir harcamayı benimsemiştir (Tabakoğlu, 2012:265). Osmanlı Devleti mali sisteminde bir bütçe geleneğinin olduğu, ancak bu bütçelerin gerek batılı ülkelerde gerekse de günümüz modern parlamenter sistemlerde kullanılan bütçelerle aynı olduğu anlamına gelmez. Genel olarak bütçe kayıtları, merkezi hazinenin gelir ve giderlerini kayıt altına almaya yönelik olarak düzenlenmiştir (Belin, 1999:175).

Devletin mali yapısı; merkezi hazine (hazine-i amire), tımar alanları ve padişah hazinesinden yani iç hazineden meydana gelmiştir (Cezar, 1986: 28). Tımar sisteminin zayıflaması sonucu bu yolla sağlanan vergi gelirleri azalınca, bütçe açıklarının finanse edilmesinde iç hazine kaynakları kullanılma yolunu tercih edilmiştir. Bu gelişmeler karşııında XVII. Yüzyılın sonlarına doğru, krizlerin yoğunlaştığı eyaletlerden gelen irsaliyelerin azalması sonucu merkezi idare gelir kaygııına düşmüş; bazı eyalet hazinelerini kaldırarak vergi toplama yetkisini iltizam yoluyla voyvodalara ve muhassıllara bırakmıştı. (Genç ve Özvar, 2006-C1: 19-21; Akkuş,2013:147-178).

Devlet vergilerin ancak bir kısmını toplayabilir hale gelmesi sonucu merkezi hazinenin gelir giderleri denkleştirmekte güçlükle karşılaşmışırı. Nitekim bu konuda Ahmet Lütfi Efendi, hazinenin giderleri karşılama güçlüğü ile karşı karşıya kalındığında "edna bir emrü işaretle bir günde tahvilsiz binlerce kise alınır verilirdi" şeklinde dile getirmesi devlet hazinesinin bütçe açıklarını geçici tedbirlerle ortadan kaldırıldı̆ına işaret etmektedir (Lütfi, 1984:105). Tanzimat dönemi bütçelerine değinildiğinde daha ayrıntılı bir şeklide izah edileceği üzere 1851 yılında hazinenin açıklarını kapatmak üzere Fuat paşa'nın girişimleriyle i̇ç borçlanmanın (esham) dışında dış borçlanma gibi yöntemlere baş vurulması gündeme gelmiştir (Cevdet,1986:23). Ancak Kırım savaşı sırasında 1854'de ingiltere'den oldukça yüksek faizle ilk dış borçlanma gerçekleşecektir (Tabakoğlu, 2012:289).

\section{Klasik Dönemde Bütçe Uygulaması}

Osmanlı Devlet hazinesinin yıllık gelir ve gider rakamlarını içeren cetveller kuruluşundan itibaren mevcuttu. Konuya ilişkin yapılan çalışmalarda söz konusu cetvellerin, Tanzimat dönemine kadar hazinenin gelir ve giderlerini gösteren tablolar olduğunu yönündedir. Ayrıca bu cetvellerin modern anlamda bir bütçe özelliği taşımadığı, envanter yahut kesin hesap mahiyetinde olduğunu, çoğunlukla yıl sonunda tutulan hesap özetleri niteliği taşımasıdır (Sahillioğlu, 1989: 44-46).

16. ve 17. Yüzyıllarda dünyada henüz bütçe deyimi bilinmiyordu. Osmanlılar "icmal-i varidat ve masarifat-ı hızane-i amire" veya "muhasebei varidat ve mesarifat-i hızane-i amire" adıyla hesap defterleri tutmuşlardır. Bu defterlere hazinenin gelir ve gider özeti veya hazinenin gelir ve gider muhasebesi denilmektedir.

Başlıca merkezi hazine gelirlerinin \%90'ı aşağı yukarı eşit paylara sahip üç tür vergiden sağlanıyordu. Bunlar; aşar ve ağnam resmi, emlak vergisi, gümrük resimleri ve dolaylı vergiler ile birlikte ganimet, maden resmi, gümrük resmi, esnaftan alınan ihtisab resimleri, barış veya savaş zamanında toplanan çeşitli örfi vergiler ile eyaletlerin gelir fazlası ve imtiyazı eyaletlerin yıllık maktu vergilerinden oluşmakta idi. Geri kalan miktar, gayrimüslim uyruklulardan alınan cizye ile Mısır, Boğdan, Eflak ve Sırbistan'dan alınan vergilerdi (Tabakoğlu,2012:282).

Gelirlerin yaklaşı üçte birini oluşturan aşar, ayni olarak ödeniyordu ve alışılmış vergi tahsilat yöntemi ise iltizamdı. Osmanlı İmparatorluğu, Gülhane Hatt-ı Hümayununda açıklanan program doğrultusunda, dolaylı vergi tahsilatı (iltizam) yerine doğrudan tahsilat denemeleri yapmış, fakat vasıfı personel eksikliği yüzünden bu denemeler hazine gelirlerinde önemli bir azalmaya yol açmıştır. Bu nedenle, iltizam sistemine geri dönülmek mecburiyetinde kalınmıştır (Autheman, 2002: 16).

Osmanlılarda modern anlamda bütçenin olmaması Osmanlı Devleti'nin güvenilir mali kayıtlarının olmadığı anlamına gelmez. Nitekim bu konuda Tabakoğlu (2005), söz konusu gelir ve giderlerin kayıt altına alınmasına yönelik olarak bütçe tanımlanmasında bir yanlışlığın ve eksikliğin olmadığını ileri sürmektedir. Ömer Lütfi Barkan ve Halil Sahillioğlu’nun yapmış olduğu çalışmalara göre ilk Osmanlı bütçesi 11.3.1524-10.3.1525 tarihlidir. Daha sonra 1527-1528, 1547-1548, 1567-1568, 1660-1661 ve 1669-1670 yıllarına ait bütçeler yayımlanmıştır (Barkan,1955; Sahillioğlu,1985). Barkan ve Sahillioğlu’nun öncü çalışmalarını 1980'li yıllardan itibaren Ahmet Tabakoğlu, Yavuz Cezar ve Tevfik Güran'ın eserleri takip etmiştir (Genç ve Özvar, 2006: 7). Tanzimat dönemine kadar geçen devrede Osmanlı Devletinin safi varidat ve masrafları müfredatıyla çeşitli defterlere kayıt olunmuştur. Tahmin esasına dayanan genel bir devlet bütçesinin yapılmasına ihtiyaç duyulmamıştır. Daha öncede belirtiğimiz gibi Osmanlılar 16. Yüzyılın sonlarına dek mali problemlerle ciddi şekilde karşılaşmadıklarından gelire göre hareket etmekte olduklarından dolayı tahmini bütçe ihtiyacı hissetmemiş olabilirler. XVII. yüzyılda tutulan muvazene defterleri tahmin ve tasdik esasına dayanmayan ve harcama yapıldıktan sonra tutulan hazine hesap hülasalarıydı. I. Ahmet zamanında 1609'da Ayni Ali Efendi tarafından tanzim edilen İstanbul'un senelik masraflarına dair cetveli. IV. Mehmet döneminde 1654 yılında Tarhuncu Ahmet Paşa Layıhası ile 1660 tarihli Eyyubi Efendi'nin ve 1653-54 yılına ait Ali Ağa'nın hazırladıkları cetveller bütçe niteliğinde en meşhurlarıdır. Tarhuncu layihasındaki bütçenin geliri 14.503 kese (7.250 .000 akçe), gideri ise 16.400 kese (8.200.000 akçe) idi.( Bir yük 100000 akçe; Bir kese 500 akçe karşılığıdır).Bu layihadan bütçenin 1900 kese (950.000 akçe) açığı olduğu ve 1.5 yıllık gelirin de önceden alındığı belirtilmiştir (Belin, 1931:4950). Bütçeye benzeyen bu hesap defterlerindeki varidat ve masraf miktarları masraf lehine görülen açık miktarları da belirtilmiştir (Karamürsel, 1940:118-119). 


\section{Tanzimat Dönemi Bütçe Uygulamaları}

Osmanlı devletinde Tanzimat'ın ilanından yaklaşık bir yı önce $1838^{\prime}$ de defterdarlık teşkilatı yerine Maliye Nezareti kurulmuş ve mevcut hazinelerin 1840 'da Redîf ve Mansûre Hazineleri ile Hazine-i Âmire birleştirilerek Hazine-i Celile-i Maliye adıyla tek hazine sistemine geçilmiştir. Osmanlı Devleti Bütçe kavramını ilk olarak bu dönemde çerçeve karar 1845'te ortaya çıkmış dolayısıyla sistemin değișmesiyle en önemli icraat 1846'dan itibaren modern anlamda tahmini bütçelerin devreye sokulmasıdır (Güran, 1989:7). Tanzimat Fermanındaki" Devleti Aliye'nin berren ve bahren mesarif-i askeriye vesairesi dahi kavanin-i icabiye ile tahdit ve tebyid olunup ona göre icra olunması lazimedendir" (Düstur, I.Tertip, c.ı., s. 4-7), ifadesinde Kavanin-i icabiye ile masrafların tahdid ve tebyini hükmünün gelirsiz masraf yapılamayacağına göre gelirin de kayıt altına alındı̆̆ını göstermektedir. Bu ifadelerden Tanzimat Fermanında dolaylı olarak bütçe vurgulanmaktadır. 1856 Islahat Fermanında da "... sa1tanat-ı seniyyenin beher sene için varidat ve masarifat defterlerinin tanzim ve iraesi hakkında muahhar bir nizam-ı mahsus yapılmış olduğundan bunun temami-i icra-ı ahkamına itina Olunması" (Düstur,ı.Tertip, c.ı., s. 7) cümlesi ile bütçe için daha açık bir ifade kullanarak muvazene defteri nizamname hüküm altına alınmıştır (Şener, 2007:5). Tanzimat Fermanı herkesten maddi gücü nispetinde vergi tahsil edilmesini, arpalık ve aidat usulünün terk edilerek yerine maaş sisteminin ikame edilmesini ve Hassa Hazinesi ile giderlerinin Maliye Hazinesi'ne dahil edildi(Feyzioğlu,1981:27)

Nizamiye hazinesinin yürürlüğe girmesinden itibaren Eyalet ve sancaklarda maliye işlerinin yürütülmesi ve vergilerin doğrudan hazine adına toplanması için muhassıllar görevlendirilmiştir. Söz konusu uygulamadan verim alınamadığından dolayı 1842'de iltizam sistemine yeniden dönülerek muhassıllıklar kaldırılmış ve eyaletlere defterdarlar atanmıştır (Kılıç, 2002:359). Artık devletin hazineleri tüm gelir ve giderlerini bünyesinde toplayacak şekilde tek bir hazine olarak faaliyet gösterecektir. Maliye Nezâreti tüm malî işleri kontrol eden bir idare haline getirilerek bütçede olması gereken birlik ve genellik prensiplerine uygun bütçelerin hazırlanması imkân dâhiline girmiştir. Buna karşılık Tanzîmat'ın ilk yıllarında bütçeyle ilgili herhangi bir düzenlemeye de gidilmemiştir (Şahin, 2013: 853-868).

Bir diğer gelişmede Osmanlı Devleti mali ve para politikasına yönelik yeni bir uygulamaya geçmiştir.1844 yılında, paranın değerini korumak amacıyla, Batılı ülkelerin önerileri doğrultusunda, Tashih-i Sikke ya da Tashih-i Ayar olarak adlandırılan bir para reformu yapılmıştır. Bu reformla; altın ve gümüşe dayalı yeni bir para sistemine (çift metal sistemi) geçilmiş ve ondalık sistem benimsenerek lira ve kuruş esası devreye girmiştir (Öner, 2001: 306). 1846-1855 yılları arasında bütçeler söz konusu usule göre hazırlanmakla birlikte, bununla ilgili yapılmış herhangi bir hukuki düzenleme bulunmamaktaydı. Daha sonra 1855 yılında bütçelerin hazırlanması, onaylanması ve denetlenmesi ile ilgili esasları belirleyen Hazine-i Celîlenin Muvazene Sureti Tanzimine Dair Nizamname kabul edilmiștir. Bu dönemde kesin hesap sonuçlarını Meclis-i Muhâsebe-i Maliye'nin incelemesi öngörülmüştür. (Şahin, 2013:853-868) Bu nizamname ile bütçe, yasama organı tarafından devlet gelirleri ve giderlerini denetler mahiyette bir nitelik kazanması üzerine izne tabi tutulmuştur (Şener, 2007:10).

\section{II. Meşrutiyet Dönemi Bütçe Uygulamaları}

Bütçe hakkı yani vergilerin esas ve oranlarıla bunların harcanacağı yerlerin ve miktarının belirlenmesi 1876 'da yürürlüğe giren ilk anayasa olarak kabul edilen Kanun-ı Esasíssi ile tanınmıştır. Bu anayasanın 20, 25, 96 ve 97. Maddelerinde verginin tasdiki ve bütçe hakkı kayıtlara girmiştir. Bu hükümlerle Osmanlı Anayasası vergi tasdik hakkı ve bütçe hakkını açık ve kesin bir şekilde kabul etmektedir. Yine anayasanın 98 . ve 102. maddelerinde bütçenin yıllık olma prensibi ile gelir ve giderlerin bölümler itibariyle tasdik edilmesi yöntemi tespit edilmiştir. (Feyzioğlu, 1981:29; Şahin, 2013:853-868).

Kanun-ı Esasî, bütçe hakkını Mebusan Meclisi ile Ayan Meclisinden kurulu Meclis-i Umumi'ye vermiştir. Kanun-i Esasî'de kanuni dayanağı olmaksızın kimseden vergi, resim adı altında para tahsil edilemeyeceği, devlet gelir ve giderlerinin her yıl Muvâzen-i Umumiye Kanunu ile tasdik edildikten sonra icra edileceği ve vergilerin tahsiline bütçe kanunu ile her yıl yeniden mezuniyet verilmesi gerektiği belirtilmiştir. Ancak bu esaslar, 1908'de II. Meşrûtiyet'in ilanına kadar fiilen uygulanamamış, vergiler padişahların iradeleriyle toplanmaya ve padişahın uygun gördüğü yerlere harcanmaya devam edilmiştir. (Şahin, 2013:853-868). Gelir ve gider kalemlerinden oluşan yerel ve merkezi bütçelerin birleştirilmesi "Birlik ilkesine" tam anlamıyla uyum ise 1909-10 mali yılı bütçesiyle gerçekleşmiştir. Aşağıda 1880 ile 1910 yılları arasında dairelere göre ayrılan bütçe rakamları yer almaktadır.

\section{Tablo 1: 1880-1910 Yılları Arasında Dairelere Göre Bütçenin Dağılımı}

\begin{tabular}{|l|c|c|}
\hline Daireler & 1880-1881 Bütçe/Lira & $1909-1910$ Bütçe lira \\
\hline Donanma & 989.015 & 1.228 .840 \\
\hline Hazine-i Hassa & 156.218 & 522.570 \\
\hline Dahiliye & 1.032 .133 & 1.085 .112 \\
\hline Yasama Kurumları (Devlet Şurası hariç) & 112.500 & 215.346 \\
\hline Maliye & 1.503 .594 & 2.723 .234 \\
\hline Duyun-ı Umumiye & 6.507 .009 & 8.294 .262 \\
\hline Ordu (Donanma ve Tophane hariç & 7.237 .385 & 8.280 .542 \\
\hline Sadrazam & 35.554 & 34.490 \\
\hline Adalet & 403.990 & 651.917 \\
\hline ilmiye & 189.768 & 485.433 \\
\hline Eğitim & 96.414 & 660.527 \\
\hline
\end{tabular}

Kaynak : Devlet-i Aliye'nin 1296 yılına ait Muvazene-i Umumiyesi ve .Devlet-i Osmaniye'nin 1323 yılı Bütçesi; Keskinkılıç, Pdf.

1887 tarihli muhasebe kayıtlarında hazinenin gelirlerinden Osmanlı ailesine mensup olanlar ile saray hizmetinde bulunan bir kesimine ödenen maaşlar aşağıda gösterilmiştir. Osmanlı Devleti'nin üst düzey ricaline ve hanedan üyelerine ödenen maaşlar Rumi takvime göre (Mart, Nisan, Mayıs, Haziran, Temmuz, Ağustos, Eylül, Teşrin-i Evvel, Teşrin-i Sani, Kânun-i Evvel, Kânun-i Sani, Şubat aylarında birkaç istisna dışında her 
ay maaş ödenmekte idi. Bu verilere bakıldığında en fazla 500.000 kuruş ile “Devletlü Valide Sultan Alişan Hazretleri”ne ödenen maaş öne çıkmaktadır. Diğerlerine kademeli olarak belli oranlarda maaş bağlandığı görülmektedir. Maaş büyüklüğüne göre tablo-II'de isimleri sıralanmıştır.

\section{Tablo 2: Aylık Olarak Ödenen Maaşlar}

\begin{tabular}{|c|c|c|}
\hline İsimleri & $\begin{array}{l}\text { Rûmi takvime göre Her ay maaşlar } \\
\text { ödenmiş. }\end{array}$ & Maaş Miktarı/Krş. \\
\hline Valide Sultan Alişan Hazretleri & & 500.000 \\
\hline Adile Sultan & & 200.000 \\
\hline Fatma Sultan & & 125.000 \\
\hline Refika Sultan & & 125.000 \\
\hline Cemile Sultan & & 125.000 \\
\hline Murat Efendi & & 125.000 \\
\hline Abdulhamid Efendi & & 100.000 \\
\hline Reşat Efendi & & 100.000 \\
\hline Burhanettin Efendi & & 35.000 \\
\hline Kemalettin Efendi & & 40.000 \\
\hline Nureddin Efendi & & 30.000 \\
\hline Süleyman Efendi & & 20.000 \\
\hline Vahideddin Efendi & & 20.000 \\
\hline Behiçe Sultan & & 15.000 \\
\hline Seniha Sultan & & 15.000 \\
\hline Mediha Sultan & & 15.000 \\
\hline Naile Sultan & & 15.000 \\
\hline Alaaddin Efendi & & 16.330 \\
\hline Seniye Hanım Sultan & & 50.000 \\
\hline Feride Hanım Sultan & & 50.000 \\
\hline Kadın Rab’i Sultan Mahmud Han & & 34.744 \\
\hline Baş İkbal Müşarün-ileyh & & 34.744 \\
\hline İkbal Salis Müşarün-ileyh & & 34.744 \\
\hline Kadın Sani Abdulmecid Han & & 20.000 \\
\hline Kadın Salis Müşarün-ileyh & & 20.000 \\
\hline Kadın Rab-i müşarün-ileyh & & 20.080 \\
\hline Kadın Hams Müşarün-ileyh & & 20.000 \\
\hline Baş İkbal Müşarün-ileyh & & 20.080 \\
\hline İkbal Sani Müşarün-ileyh & & 15.000 \\
\hline İkbal Salis Müşarün-ileyh & & 15.000 \\
\hline Müşarün-ileyhin civarları & & 17.430 \\
\hline Kayıkçıyan Saltanat ve saire & & 82.063 \\
\hline
\end{tabular}

Kaynak: BOA, Devlet-i Aliye-i Osmaniyenin 1303/1887 tarihli Varidat ve Mesaarifat Defteri, s.9. 


\section{SONUÇ}

Osmanlı merkezi bütçesi, merkez bürokrasisi olan Divan-ı Hümayun ve buna bağlı kalemler, şeyhülislam ve ilmiye teşkilatı, askeri teşkilat, defterdarlık ve maliye teşkilatlarının giderlerinden ibaretti. Merkezi bütçeye ilave olarak eyalet ve vakıflar bütçeleri bulunmakta ve merkez bütçeleri bunlardan aktarılan gelirlerle birlikte hesaplanmaktaydı. Eyalet ve vakıflar kendi gelirleri ile giderlerini karşılamakta ve gelir fazlalarını merkeze göndermekteydiler. Dolayısıyla Osmanlı merkez bütçeleri, birçok kamu hizmetinin yerelde ve yerinden, vakıflar aracılığıyla, gerçekleştirdiği söylenebilir

Tanzimat öncesi dönemler genellikle Osmanlılar bütçeleri oluştururken, modern anlamda bütçe ilkeleri arasında bulunan kapsamlılık (genellik) niteliğine yer verilmemiştir. Ancak mevcut bütçeler devletin bütün gelir ve giderleri içerisinde sadece merkezi idarenin belirli gelir ve giderlerini içermektedir. Osmanlı yönetiminde olan bölgelerden toplanan vergi gelirleri, has, zeamet ve tımar şeklinde veya çeşitli imtiyaz ve vergi muafiyetleri durumunda askeri ve idari hizmetlerin karşılığı olarak bırakılmış, bazı vergiler ise dini, kültürel veya toplumsal açıdan karşılanması gereken bazı ihtiyaçların giderilmesi adına kurulmuş olan vakıflara tahsis edilmiştir

Esasında Osmanlı Devleti'nde modern anlamda bütçelerin hazırlanması ve daha sonraki dönemlerde de uygulanmasında bütçe gelir-gider tahminleri bir önceki yıl hesapları dikkate alınarak çıkartııır ve bütçenin bir örneği padişaha, bir örneği de Meslis-i Vâlấya sunulmak üzere yayımlanırdı

Tanzîmat sonrasında oluşturulan heyetler ve kurumlarla padişahın yasama yetkisi ve bu arada halka malî yükümlülükler koyma gücü paşalar ve bürokratlar tarafından sınırlandırılmaya çalışılmıştır. Diğer taraftan 1910'dan itibaren ülke içerisinde yapılan her harcama ve toplanılan her gelir devlet bütçe/hazine kayıtlarında yer alacaktı. Böylece bütçenin "genellik ilkesi" de kabul edilmiş ve kayıtlara girmiş oluyordu

Bütçelerde Osmanlı ailesine mensup olanlar ile saray hizmetinde bulunan bir kesimine ödenen maaşlar aşă̆ıda gösterilmiştir. Osmanlı Devleti'nin üst düzey ricaline ve hanedan üyelerine ödenen maașlar Rumi takvime göre her ay maaş ödenmekte idi.

\section{KAYNAKÇA}

Başbakanlı Osmanlı Arşivi

Maliye Vâridât Muhasebesi Defterleri

Barkan, Ö. L. (1960). H. 954-955 (M.1547-1548) Malî yılına ait bir Osmanlı Bütçesi, íFM, C.19. S.1-4'den ayrı basım, Sermet Matbaası, İstanbul.

Barkan, Ö. L. (2000). Osmanlı Devleti'nin sosyal ve ekonomik tarihi, tetkikler-makaleler. Cilt:1, iü Rektörlük Yayını No:4214, if Yayını No:565, TiiTAM Yayını No:3, Yay. Haz.: Hüseyin Özdeğer, İstanbul.

Barkan, Ö. L. (1955). Osmanlı İmparatorluğu bütçelerine ait notlar. İstanbul Üniversitesi İktisat Fakültesi Mecmuası, C. 17, No. 1-4, İstanbul.

Feyzioğlu, B. N. (1981). Nazari, Tatbiki, Mukayeseli Bütçe. 6. Baskı, Filiz Kitabevi, İstanbul.

Genç, M., Özvar, E. (2006). Osmanlı Maliyesi kurumlar ve bütçeler 1,2. Osmanlı Bankası Arşive ve Araştırma Merkezi, I. Baskı, İstanbul.

Güran, T. (1989). Tanzîmat Döneminde Osmanlı Maliyesi: bütçeler ve hazine hesapları (1841-1861). TTK Yayınları, Ankara.

Karamürsel, Z. (1940). Osmanlı malî tarihi hakkında tetkikler. TTK Yayını, VIII. Seri-No. 11, Ankara.

Keskinkılıç, E. file://C:/Users/PC/Downloads/5000085456-5000119412-1-PB\%20(1).pdf. erişim:3.5.2018.

Kılıç, S. (2002). 1855 bütçe nizamnamesi ve uygulaması. Türkler, C.16, Ankara.

Lütfi, A. E. (1931). Vak'anüvis Ahmet Lütfi Efendi tarihi, Yay. Haz. M.Münir Aktepe C.IX, İstanbul 1984.

Öner, E. (2005), Osmanlı İmparatorluğu ve Cumhuriyet Döneminde malî idare. TC Maliye Bakanlığı APKKB Yayını No:2005/369, 2. Baskı, Ankara.

Sahillioğlu, H. (1984). 1524-1525 Osmanlı bütçesi. iüiFM, C.41, S.1-4, Eylül 1982-Ekim 1983, İstanbul.

Şener, A. (2007). Sona doğru Osmanlı. Birleşik Kitabevi, Ankara.

Tabakoğlu, A. (2012). Türk iktisat tarihi. Dergâh Yayınları, Tarih Dizisi, İstanbul.

Tabakoğlu, A. (1999). Osmanlı malî yapısının ana hatları. Osmanlı, C. 3: İktisat, Yeni Türkiye Yayınları, Ankara.

Uzunçarşılı, İ. H. (1978). Osmanlı Devleti maliyesinin kuruluşu ve Osmanlı Devleti iç hazinesi. Belleten, C.42, S. 165, Ocak. 